\title{
No Time to Move: Motion, Painting and Temporal Experience
}

Forthcoming in Pbilosophy.

\begin{abstract}
This paper is concerned with the senses in which paintings do and do not depict various temporal phenomena, such as motion, stasis and duration. I begin by explaining the popular - though not uncontroversial - assumption that depiction, as a pictorial form of representation, is a matter of an experiential resemblance between the pictorial representation and that which it is a depiction of. Given this assumption, I illustrate a tension between two plausible claims: that paintings do not depict motion in the sense that video recordings do, and that paintings do not merely depict objects but may depict those objects as engaged in various activities, such as moving. To resolve the tension, I demonstrate that we need to recognise an ambiguity in talk of the appearance of motion, and distinguish between the depiction of motion and the depiction of an object as an object that is moving. Armed with this distinction, I argue that there is an important sense in which paintings depict neither motion, duration, nor - perhaps more controversially - stasis.
\end{abstract}


People call me the painter of dancing girls. It has never occurred to them that my chief interest in dancers lies in rendering movement and painting pretty clothes'. - Edgar Degas, in conversation with Ambroise Vollard (1937, p. 87)

\section{Overview}

Famous for his paintings of ballerinas, Degas was particularly interested in dance and motion. He would often paint dancers in unstable positions, such as balancing on one foot, in an effort to 'introduce movement into a painting' (Gottlieb, 1958, p. 22). Viewing Degas's works we might wonder how successful he is, and indeed can be, in this effort.

From a survey of the literature, and of people's opinions, intuitions seem to pull in opposing directions. I am particularly interested in two claims that people have found intuitively plausible, but which, at least at first glance, appear to conflict. Firstly, people find it plausible that paintings do not depict dynamic occurrences, such as an object moving or undergoing qualitative change (in colour, for example), in the sense that motion pictures do. Secondly, people also find it plausible that Degas's paintings do not merely depict dancers, they depict dancers as dancing (where this is to be distinguished from paintings of figures as sitting, or as standing still). There is, at face value, an intuitive sense in which paintings both do (as illustrated by the dancer dancing) and do not (as illustrated by the contrast with motion pictures) depict figures moving.

My concern in what follows is with the apparent tension between the two aforementioned plausible claims about the phenomena that paintings depict (to be discussed in \$3) - i.e. how a subject/object can be depicted as moving if motion is not depicted. In the final section ( $(\mathbb{4})$, I turn to a related issue that comes to the fore in a discussion from Gombrich (1964), and in a response from Le Poidevin (1997): the temporal extent that a painting does or does not depict - i.e. is the scene depicted depicted as occurring at a particular instant, over a particular interval, or neither?

Ultimately, I argue that paintings do not depict motion (or stasis) - though this is to be distinguished from the sense in which an object may be depicted as an object that is moving (or stationary). I maintain that a painting does not depict motion (or stasis) because the duration of 
the scene is not depicted, the scene depicted is neither depicted as occurring at a particular instant, nor over a particular interval. To begin, I outline precisely how the notion of depiction is being understood.

\section{Depiction}

\subsection{Representation and depiction}

There are numerous ways for a given medium, such as a painting, to represent. Take a given painting to show a large tree in a field, surrounded by townspeople. The warm yellows and oranges of the painting may represent the colours of the tree's leaves; the text the painter chose to scrawl on a sign in the painting - say, 'Blesle' - may represent that the scene is in a French village; the people in the field may represent hope and a sense of community. These features may all be represented, but they are not represented in an alike manner.

It is plausible that 'one form of representation is specially pictorial...' and that 'there is a form of representation that is distinctively exhibited by pictures and that it is distinctive of pictures to exhibit' (Hopkins, 1995, p. 425). I take it that the term depiction is used to single out this specially pictorial form of representation. As different means of presenting information, depiction can be contrasted with (for example) linguistic representation. I may describe the scene to you verbally (or in written text, as above), and you can thereby come to know of the tree, the people and the village. However, the way(s) in which my speech represents the scene appears to be markedly different from the way in which the painting represents the scene. This underlies the intuition that there is something specially pictorial about the latter, but not the former. It is plausible that the painting depicts the leaves, tree and field; not hope or a sense of community.

There are various accounts of the nature of depiction; one way that theorists have cashed out the intuition that depiction is specially pictorial is in terms of an experiential resemblance between the pictorial representation and that which it is a depiction of. ${ }^{1}$ Such accounts of depiction are often presented as developing Wollheim's (1987) claims about what he calls the twofoldness of the experience of pictorial representations. For Wollheim, this terminology is used in order to signify

\footnotetext{
${ }^{1}$ For an overview, see Hyman and Bantinaki (2017).
} 
that, in observing a painting: 'I am visually aware of the surface I look at, and I discern something standing out in front of, or (in certain cases) receding behind, something else' (Wollheim, 1987, p. 46). The subject is said to see the marks made on the surface of a canvass - such as the warm yellow and orange brush strokes - and, in the same experience, she is said to 'see-in' the painting the object that is depicted - such as the leaves of a tree. Many influential accounts develop Wollheim's twofoldness claim and explain depiction through appealing to resemblances between two-dimensional shapes on the surface of the image (photographs, paintings, and so on) and the spatial contours of the objects - relative to an experiencer's point of view in space - that are said to be depicted. ${ }^{2}$

If we are to think of depiction in terms of a resemblance in shape (between marks on the surface of the image and the objects said to be depicted), then on the plausible assumption that temporal properties - such as motion - are not to be thought of as an aspect of an object's shape, the depiction of the temporal - i.e. motion - would appear to be ruled out without any further investigation. 'So be it', you might think. To be sure, theorists holding such a view of depiction might not be troubled by this result. They may be thoroughly convinced of the claim that paintings do not depict dynamic properties (such as movement and change) in the sense that motion pictures do, and they may be happy to provide an explanation of why - because, on their view, depiction is concerned with resemblance between shapes. However, as said at the outset, some also find it plausible that Degas's paintings do not merely depict dancers, but that they depict dancers as dancing. Such people will be most dissatisfied by a view of depiction on which the depiction of the temporal is ruled out by definition and with no further explanation. To avoid this tension - in an attempt to reconcile the two intuitions highlighted at the outset - I will opt for a broader account of depiction.

It may be that some such accounts of depiction are too narrow, if only appealing to resemblances in shape, in order to capture everything that we might want to say is depicted. Alternatively, it may be that an appeal to resemblances in shape is best thought of as merely a representative example of what are ultimately more nuanced accounts of depiction. Regardless, we can hold onto much

\footnotetext{
${ }^{2}$ We find different proposals that seek to explain pictorial depiction in terms of experienced resemblance in shape in Budd (2008a and 2008b); Hopkins (1998); Peacocke (1987); and Wollheim (1987, 1998, and 2003). In contrast, Hyman (2006 and 2012) proposes a resemblance theory of depiction which is cashed out in terms of spectator-independent resemblance. Also see Abell (2009) for a proposal that gives a greater role to the intentions of the artist.

${ }^{3}$ I suggest this as a plausible line of reasoning, but not one which I mean to be committed to. In $₫ 3.1 \mathrm{I}$ suggest that this is an oversimplification and that there may be a role for resemblances in shape in depicting something of a temporal nature - i.e. depicting an object as an object that is moving in a given way.
} 
of the intuitive force behind the experienced resemblance theories of depiction without being solely focused upon shape - and so without yet ruling out the depiction of motion.

We can capture what is specially pictorial about depiction by holding that depiction is concerned with visual appearances, where this includes, but is not limited to, visual shape. ${ }^{4}$ This is how I will understand depiction: pictures depict objects/states of affairs through capturing and presenting their visual appearances. It follows that, in order to depict some object (or an occurrence, a state of affairs, or a visual property) it is necessary to present, in an image, some visual appearance resembling the visual appearance of that object (or occurrence, state of affairs, or visual property). This is the core of the proposal regarding depiction that I shall operate with, but if it is to be of any use in the current context it first needs to be spelled out further.

As I see it, three important clarifications need to be made: Firstly, how does this proposal relate to the intuition that we see something as an image/pictorial representation, in addition to being aware of that which is depicted? This being the intuition behind Wollheim's appeal to the 'twofoldness' of the experience of pictorial representations. Secondly, what are visual appearances, such that they may be presented in an image? Thirdly, given that almost any given object may be said to resemble any other object in some respect - at the very least, by both being objects - what constrains the sense in which one visual appearance must resemble another in the case of depiction? That is, by what metric are we to say whether a pattern on the surface of an image resembles the visual appearance of that object that is said to be depicted? I address these issues in $\$ 2.2$, below.

\subsection{Depiction and visual appearances}

Operating with an account of depiction in terms of visual appearances, we can distinguish between cases in which we see something as an image/depiction of some object $\mathrm{O}$, and cases in which we illusorily take ourselves to be presented with the very $\mathrm{O}$. In seeing something as an image, as some form of depiction of the $\mathrm{O}$, we see that image as presenting the visual appearance of that $\mathrm{O}$ while manifestly being something other than the $\mathrm{O}$-i.e. being an image. ${ }^{5}$ In the case of a perfect trompe

\footnotetext{
4 The idea that depiction is a matter visual appearance more generally is suggested in passing by O'Shaughnessy, who says that '...the arts of painting, sculpture, and architecture, are more or less exclusively concerned with visual appearances...' (O’Shaughnessy, 2000, p. 571). Such a view of depiction is also suggested by Hopkins (1995, esp. p. 434) and developed by Martin (2012).

5 This point is made by Martin, who says 'a visual image presents the appearance of something which it does not exemplify.... To recognize an image for what it is, on this view, will be to see that it presents an appearance which it
} 
l'oeil, we are unaware that what we are seeing is an image and, through the visual appearance of an $\mathrm{O}$ being presented we simply take ourselves to be presented with the very $\mathrm{O}$. Taking it that in seeing something as an image, as some form of depiction of the $\mathrm{O}$, we see that image as presenting the visual appearance of that $O$ while manifestly being something other than the $O$, we now require an account of visual appearances.

Martin (2010) takes visual appearances to be a matter of the 'visually basic properties' of objects (Martin, 2010, p. 207). These properties are, by and large, a matter of observational properties, such as size, shape, colour, visible texture, and the spatial arrangement of parts. ${ }^{6}$ These visually basic properties are said to be the properties by which we can tell whether or not two objects visually resemble each other. In what follows I will take visual appearances to be a matter of such properties. ${ }^{7}$

Before I proceed to spell out the relevant notion of resemblance, I want to signpost and dismiss a worry that I have heard raised. I have so far followed Martin in presenting visual appearances as the visually basic properties of objects. This suggests that to see an image as depicting some $\mathrm{O}$ is to be presented with the visual appearance of that $O$ by something that is manifestly other than the O. At this point, in the context of the present discussion, a theorist might interject and say that motion/change simply is not a visually basic property of an object - that it is not a visually basic property of a spatial particular, as opposed to being a property of some state of affairs, perhaps and so it cannot be presented (i.e. depicted) in such images. However, ruling out the depiction of motion on these grounds is unlikely to satisfy the reader (for much the same reason as with the focus upon resemblance in shape). We might question why motion shouldn't be thought of as a visually basic property of a spatial particular, rather than of a state of affairs. Alternatively, we may press that images display the visual appearances of states of affairs, where this involves objects but also properties such as motion/change. On either line of response, there is as of yet no reason to

does not exemplify' (Martin, 2012, p. 343). I cannot adequately explore Martin's view in the present context, but it should be acknowledged that the general proposal regarding depiction that I operate with is indebted to Martin (which is not to say that he would accept the overall picture or claims that I offer).

${ }^{6}$ Martin characterises observational properties as 'those properties that necessarily are visually unique. That is to say, observational properties are those properties for which necessarily no object that exemplifies them, and is characteristic with respect to look for that property, has a visual duplicate that lacks them' (Martin, 2010, p. 203). Observational properties, and so visual appearances, may be taken to be properties of objects rather than being distinctive special objects of sense; where 'the overall look of an object is a function of its observational properties, and the various ways of looking it may share or contrast with other objects are just conjunctions or disjunctions of the observational properties it has' (Martin, 2010, p. 206).

${ }^{7}$ Martin says that the visually basic properties may also include some nonobservational properties; here he focuses upon the look of solidity and how a perfect hologram may look solid even though it is not. 
think that images cannot present the appearance of motion; I have nothing to say here against either suggestion. Instead, I will turn to the third issue raised above.

Taking the depiction of an object to be a matter of something that is manifestly other than the object in question presenting something resembling the visual appearance of that object, the pressing issue is now by what metric we are to say whether a pattern on the surface of an image resembles the visual appearance of that object. By appealing to visual appearances and the visually basic properties of objects, the account of depiction I shall be assuming depends, to an extent, upon contingent facts about the human visual system and those properties/appearances that the system takes to be relevantly similar or distinct. To signpost, such an appeal to our visual capacities in an account of depiction may make a lot of room for boundary cases - cases where it is not clear whether or not we should say that some appearance is presented in an image - but, as I shall argue, motion/change is no such case. With regards to how we are to judge whether a pattern on the surface of an image resembles the visual appearance of a given object, we can find an intuitive test by focusing upon what subjects can learn from exposure to such images.

Assuming that pictures depict objects through capturing and presenting their visual appearances, it is plausible to suggest that such a visual appearance may be said to be presented in a picture in those cases in which exposure to the picture(s) could suffice to give subjects a grasp of the meaning of terms for the relevant appearances. In order for one thing (i.e. the pattern on the surface of an image) to resemble another (i.e. the entity that the painting is said to depict) in the relevant respect - i.e. with regard to the overall visual appearance, or at least the relevant visual property - an ordinary perceiver can come to know the meaning of the term for (and thereby linguistically refer to) such an appearance when encountering either the object or the image. ${ }^{8}$

\footnotetext{
${ }^{8}$ One may worry that this is too restrictive, and that there are cases of depiction in which the subject encountering the image cannot be said to learn the overall visual appearance of the object that people want to say is depicted (such as seeing a stickman as a depiction of a typical man). There are several points to make in response. Firstly, it may be that the proposal I am making in the text is true of what it means to depictively represent visual properties, rather than the overall looks of objects (which will plausibly involve depictively representing fewer than all of the object's visually basic properties). For the claims I make regarding motion, I would be happy to restrict my claims to what it means to depictively represent visual properties. On a second and distinct line of response, we may reply that 'depiction' is often thought of too loosely, where such a restriction would be welcome. Not all pictorial representations need be thought of as cases of depiction (the stickman being one example). Thirdly, and relatedly, it may be that there are several distinct ways of representing that are specially pictorial, such that we should be pluralists about depiction (or at least, about pictorial representation). In this case, the claims I make in the text concern one particular form of depiction, which is not to rule out there being other pictorial forms of representation that may be independently of interest.
} 
I offer the following two examples in order to clarify the proposal. Firstly, consider colour. I take it that an image can present the appearance, and redness, of a London bus. To depict the redness of a London bus in an image, the image must present (something suitably resembling) this visually basic colour property. It must be the case that a perceiver with ordinary vision will be acquainted with this colour property in encountering the image. If never having learned the linguistic terms associated with colours previously, the subject would on this basis be able to update her knowledge of what the term 'red' means by reference to the image. In teaching someone what the visual property 'red' means, we would do just as well to point at such a painted bus as we would an actual bus.

Secondly, consider depth. I take it that an image can present the visual appearance, and threedimensionality, of a wine bottle. To depict a wine bottle laid on its side, with its base towards the viewer, the image must present the relevant visual depth cues so that the typical perceiver sees its neck as further away - from her perspective - than its base. It must be the case that a perceiver with ordinary vision will be acquainted with this three-dimensional shape property in encountering the image, though the image is itself flat. In teaching someone what the visual property 'depth' means, we could, if we so desired, do so with reference to such a painting. ${ }^{9}$

To summarise the account of depiction to be assumed from hereon: to see something as an image, depicting a given $\mathrm{O}$, is to see that image as presenting the visual appearance of that $\mathrm{O}$ - or an appearance that sufficiently resembles the appearance of that $\mathrm{O}$ - while manifestly being something other than the $\mathrm{O}$. The overall visual appearance of an object or state of affairs is a matter of the visually basic properties of that object/state of affairs; these properties being, by and large, observational properties. If an ordinary perceiver can come to grasp the meaning of terms for (and thereby linguistically refer to) such an overall appearance - or visually basic property when encountering the object or the image, this is an indication that the image does present an appearance that resembles the appearance of the object - or property - in the relevant respect. In \$3 I turn to consider the central issue of interest: the apparent depiction of motion and change in images.

\footnotetext{
${ }^{9}$ Note that this is not a developmental claim about the acquisition of concepts - I am not claiming that one could acquire the concept of depth through only experiencing paintings. Rather, the claim is that we could teach someone how to apply the linguistic term associated with a given appearance (property) with reference to a painting. Thanks go to both reviewers for the journal for pushing me to clarify this section and some of the claims I make within it.
} 


\section{Dynamic Appearances}

\subsection{Painting and dynamic appearances}

Writing in the middle of the twentieth century, Gombrich laments that 'while the problem of space and its representation in art has occupied the attention of art historians to an almost exaggerated degree, the corresponding problem of time and the representation of movement has been strangely neglected' (1964, p. 293). In order to address this neglect, he says we need to revise our preconceptions about how time can be represented in various artistic media. Gombrich takes these preconceptions to be captured by Harris (1744), who says that a painting represents an instantaneous static scene.

Gombrich appears to be concerned with pressing the claim that if we can visually experience some phenomena, then that phenomena can also be represented in, for example, a painting. A key assumption in Gombrich's writing is expressed in his claim that 'as with reality, so with its representation' (1964, p. 301). Though in this context it would appear more appropriate to interpret him as claiming that as with our experience, so with representation. For example, even if time was, as it happens, quantised - composed of discrete, indivisible quanta, where each quantum consisted in static presentations of spatially ordered phenomena - this wouldn't appear to be to the point for Gombrich. In response to Harris, Gombrich is primarily concerned with our experience of temporal phenomena and pictorial representations of those phenomena. In this context he says that a painting may represent motion and change. If we hold that as with our experience, so with representation, and acknowledging that we experience objects in motion and undergoing change, he would appear to be entitled to say that motion and change may be represented in paintings.

More specifically, Gombrich appears to hold that our experience of an object in motion, when looking at a painting, is similar to our experience of the three-dimensional scene when we look at a painting: 'The impression of movement, like the illusion of space, is the result of a complex process which is best described by the familiar term of reading an image' (ibid., p. 302). When looking at Degas's The Rehearsal, ${ }^{10}$ we are aware of a two-dimensional presentation of colour which presents the appearance of a three-dimensional scene; similarly, this two-dimensional presentation of colour presents the appearance of ballerinas dancing. So goes Gombrich's reasoning.

10 https://artuk.org/discover/artworks/the-rehearsal-83736 
With reference to Gombrich's discussion, Le Poidevin suggests that, to be worth fighting over, the thesis in contention must concern depiction (see Le Poidevin, 1997, p. 183). It is granted by Le Poidevin that all parties would agree that paintings can non-depictively represent time and movement. For example, a figure may be depicted at several positions in space in an image and the audience might thereby be led to believe that the image represents a single figure moving, rather than a number of identical figures in a line. But 'pictures represent more than they depict... [and] they may represent aspects of time that they are unable to depict' (ibid.). Focusing on depiction, Gombrich appears to offer support for one of the claims offered as intuitively plausible at the beginning of the paper: that Degas's paintings do not merely depict dancers, they depict dancers as dancing - i.e. that this isn't something merely otherwise represented but not depicted.

Le Poidevin reasons that once we take Gombrich to be making the claim that paintings depict movement, we encounter an immediate objection: 'static images surely cannot trigger our capacity to recognize movement. If that were so, we would see the image as itself moving' (1997, p. 185). I take Le Poidevin's claim to be that a single static image is not sufficient to present an appearance that resembles the dynamic pattern of appearance of continuous motion. ${ }^{11}$ This appears to support the other claim offered as intuitively plausible at the outset: that paintings do not depict motion/change in the sense that motion pictures do.

To make the reach of the previous claim clearer, we can draw a distinction between perceptible and imperceptible motion. This is well demonstrated by appeal to Broad's (1923, p. 352) discussion of the hands of a clock. Assuming that the hands sweep around the clock-face in uniform motion (rather than ticking), first-personal reports of the phenomenal character of one's experience reveal that subjects see the second-hand moving, but they do not see the hour-hand moving (even if the subject was to stare at the clock-face without looking away for a whole hour). This phenomenological contrast - between perceptible and imperceptible motion - gives us the motivation for taking there to be an appearance of motion. (This leaves open whether we are to take the appearance of motion to be a property of an object or a property of an event/state of affairs.) Continuous motion (at a certain pace) - such as that of the second-hand - has a given appearance

\footnotetext{
11 Le Poidevin appeals to a subject's recognitional capacities, following Currie's (1995) recognitional account of depiction. I will continue to discuss the issue in terms of visual appearances for the reasons given previously, and also because it is not clear that an image need to be seen as moving in order for a subject to merely recognise that something is moving, depending on how we are to think of the subject's recognitional capacities.
} 
and such an appearance is not presented to an observer when she perceives paintings representing movement. $^{12}$

To put the point quite generally: It is plausible that we can be visually aware of some F-ing, such that we cannot be visually aware of such F-ing without being presented with an appearance of some relevant kind over an interval of time. The point to take from Le Poidevin is that perceptible motion, such as when one sees the pirouette of a ballerina, has a given dynamic pattern of appearance over an interval of time; this cannot be presented by anything, such as a painting, that does not present a dynamic pattern of appearance over an interval of time. These points are supported by reflection on one's visual experience of paintings, which can be contrasted with the visual experience of a moving stimulus. ${ }^{13}$

To forestall a possible misunderstanding, it is true that something can resemble the appearance of some property F without being F. This was demonstrated above by the visual property of depth, presented in the flat surface of an image. However, paradigmatically static images do not present/resemble the dynamic pattern of appearance of motion. With the visually detectable property of motion, a perceiver with ordinary vision is not acquainted with something resembling this property in encountering one of Degas's paintings, for example.

\footnotetext{
${ }^{12}$ If there is some success in creating an illusory impression of movement in a static image (see Bridget Riley's Fall [https://www.tate.org.uk/art/artworks/riley-fall-t00616] for one candidate example), is this to say that such static images depict movement? As our standard experience of motion is not directly analogous to our experience of such illusions, it is not uncontroversial to say that the appearance of one resembles that of the other in the relevant respect. Not to linger on this point, regardless of what we say of such works, without an argument to the effect that the same explanation should apply to illusions as applies to the paradigmatic cases, and acknowledging that such works are not the paradigmatic cases, the general thesis of this paper remains.

${ }^{13}$ Why, one might wonder, should we single out time, and movement/change, for special attention? Aren't there as many questions to be answered regarding how paint on a canvas can resemble a flesh-and-blood human? It is true that there are other such problems for experienced resemblance accounts to face, but I take time to be worthy of special attention in the present context for two reasons. Firstly, it has often been taken for granted that, because the properties of paintings do not change over time - at least, the properties by which they depict various objects remain more or less unchanged over time, though the painting may fade or become damaged - paintings cannot represent movement or change (understood as depending upon something occupying distinct spatial locations, or distinct properties, at successive times). This is how Gombrich construes the orthodox view in aesthetics, captured by Harris, as discussed in the text, and also by G. E. Lessing's Laocoon (1766), in which Lessing suggests painting is concerned with space, rather than time, because it can only represent one isolated moment of an action (see Gombrich, 1964, pp. 294-5). Secondly, it is plausible that given a satisfactory account of how paint on a canvas can resemble a fleshand-blood human, whether paint on a canvas can resemble change/movement remains a further issue to be settled. (But see Young and Calabi, 2018, for a proposal that draws a close analogy between the depiction of three-dimensional objects and the depiction of motion.) If we suppose that this experienced resemblance trades on resemblances in shape between paint on a canvas and a flesh-and-blood human, however this is to be spelled out (see references in footnote 2), exactly how this extends to motion/change (if it does at all) is left open. Thanks to an anonymous reviewer for the journal for pushing me to be more explicit on this point.
} 
Suppose a subject has never learned what it means to talk of the visual appearance of motion. Upon encountering a painting, the visual appearance of motion, that which is exemplified by the rotation of the second-hand of the clock, would elude such a subject. In teaching that subject what the visual appearance of motion means, we would not do just as well to point at a painting of a dancer as we would an actual dancer dancing. Paintings do not perform the role with respect to motion that they may perform with respect to depth. The phenomenological contrast between perceptible and imperceptible motion couldn't be learned through only observing paintings. However, this contrast can be learned when watching a video recording.

A video recording can present a dynamic pattern of appearance over an interval of time, and in virtue of this a video recording can present, for example, the appearance of motion - specifically the pirouetting - of a ballerina. Paintings, in contrast to motion pictures, do not present such dynamic properties or patterns of appearance over time. On the notion of depiction being assumed, the capacity of an image to present something that resembles the appearance of some $\mathrm{F}$ (or F-ing) is a necessary condition of the image depicting that F (or F-ing); the idea that motion may be depicted this way in an image appears to be ruled out.

And yet, while the contrast with motion pictures demonstrates that paintings do not depict dynamic patterns of appearance over time, this does nothing for the intuition that paintings may nonetheless depict dancers as dancing. The reader may wonder how a painting can depict a dancer as dancing if paintings do not depict certain dynamic appearances - the appearances that motion pictures plausibly can depict. We can go some way towards satisfying this intuition if we distinguish between two distinct appearances that we might otherwise fail to distinguish between because of an ambiguity in how we talk about the appearance of a dancer dancing, or more generally an $\mathrm{O}$ Fing.

We need to distinguish between (i) the appearance of F-ing, such as the dynamic pattern of appearance of motion, and (ii) the appearance of an $\mathrm{O}$ as an $\mathrm{O}$ that is F-ing, such as the appearance of a ballerina as a ballerina that is in motion. Drawing such a distinction in terms of appearances, we can distinguish between artistic media that may present the appearance of F-ing from media that may merely present the appearance of the posture or shape (for example) of an $\mathrm{O}$ as an $\mathrm{O}$ that is F-ing, which is something, strictly, different. The idea that a painting may present the appearance of some F-ing, where this is a dynamic pattern of appearance over time, has been 
denied, but we might grant to Gombrich that the painting may present the appearance of an $\mathrm{O}$ as an $\mathrm{O}$ that is $\mathrm{F}$-ing.

In the latter case, we can maintain that this is something that is visually presented - i.e. depicted in a painting, rather than merely being otherwise represented, as long as we allow that there are various ways in which being involved in a given activity can be visually manifest. The example of the ballerina pirouetting is again instructive. We can distinguish between the appearance of the pirouetting of an agent and the appearance of the bodily posture of an agent who is pirouetting where this may involve a distinctive arrangement of the limbs, or clothing. While a viewer may be presented with the pirouetting of an agent - something with a dynamic pattern of appearance over time - in a video of a ballerina dancing and not in a painting of the ballerina mid-pirouette, she may nonetheless be presented in the painting with the appearance, or something resembling the appearance, of an agent as an agent who is pirouetting. A typical painting does not depict the unfolding of some activity over time, but it may depict an agent/object as an agent/object that is engaged in some activity (as long as there is some relevant visual appearance), where it is distinctive of that activity that it unfolds over time even though the very unfolding is not depicted. ${ }^{14}$

The main claim of this section is that paintings do not present specific unfoldings of movement or change, but they may present objects as objects that are moving in specific ways. A comparison case helps to make this point clearer. Consider a case where we may wish to say that someone is (in a painting) depicted as singing, without what is sung also being depicted. This comparison requires caution because, necessarily, an image is not in the business of depicting sound. I am suggesting that likewise it is not in the business of depicting the unfolding of temporally extended occurrences. (Yet someone may be depicted as making a sound and she may be depicted as being engaged in an activity that does unfold over time.) In this case, we may say that 'the song' is doubly ruled out as something that may be depicted in an image, as something of an auditory nature and

\footnotetext{
${ }^{14}$ Reviewers for the journal ask how my proposal squares with the claim that in order to depict something as F, it is necessary to do so through depicting that thing and its F-ness - i.e. to depict an apple as red, we must depict the apple and its redness. To be explicit, I am here rejecting that claim. Such a claim appears plausible when we are concerned with an object's shape or colour, but we need not think that this generalises to all that we take to be depicted; in particular, an object's being engaged in a given activity. I maintain that there are various ways in which being involved in a given activity can be visually manifest. The F-ing of an object (i.e. the motion) need not be depicted in order for the object to be depicted as an object that is F-ing (though, in cinematic representation, the F-ing may be depicted); a certain spatial arrangement of the parts of a given figure may present that figure as dancing, as opposed to merely sitting or standing. Though my intention is not to offer or defend an interpretation of Harris, what I have said might be read as one way of developing Harris's claim that 'though to paint Motion or Sound be impossible, yet the Motions and Sounds here mentioned having an immediate and natural Connection with a certain visible Configuration of the Parts, the Mind, from a Prospect of this Configuration, conceives insensibly that which is concomitant, and hence 'tis that, by a sort of Fallacy', the Sounds and Motions appear to be painted also'. (1744, p. 62, footnote b; emphasis in original)
} 
as something unfolding over time. Contrast pictorial representation with cinematic representation and with an auditory recording. It is plausible that moving images (i.e. cinematic representation) may present the appearance of something unfolding over time, though not the auditory properties, whereas an auditory recording can present the auditory unfolding over time, but not visual. A painting, by contrast with each, depicts neither something unfolding over time nor the auditory.

\section{2. Painting and motion-blur}

This is not yet to say anything about motion-blur, which some theorists take to be a persuasive case of 'the temporal' being depicted in an image. Take as an example a camera that is set to an exposure of two seconds and focused upon passing traffic. In such a case, the camera can produce a particular photograph that captures motion-blur. One might suppose that such a photograph depicts the temporal trajectory of the cars photographed, and so depicts motion. On the conception of depiction being assumed, this cannot be quite right. ${ }^{15}$

In a typical case of motion-blur, the subject is not straightforwardly presented with the appearance of motion. Consider Locke's description of a case in which one ties a hot coal to the end of a string, before spinning it in a circle. 'For any thing, that moves round about in a Circle, in less time than our Ideas are wont to succeed one another in our Minds, is not perceived to move; but seems to be a perfect, entire Circle of that Matter, or Colour, and not a part of a Circle in Motion' (Locke, [1690] 1975, 2.14.8.20). One take away from Locke's example appears to be that the appearance of motion-blur in such a case is not equivalent to the appearance of motion.

Yet, one may question whether Locke's example captures all of the details of the situation. In the case he describes, one may think that when we see the coal, we see its movement in a distinctive, blurred way. Or, at least, there are some cases in which this is plausibly true. While I think that this is correct, we then need to address what it is that the image depicting blur visually resembles. I take it to be uncontroversial to hold that blur does not always co-occur with cases of perceived motion (plausibly, in seeing the rotation of the second-hand of a clock nothing need appear blurry), and blur can occur in the absence of motion (as when one takes off one's glasses). While there are plausibly cases in which something appears to be moving in a way that is distinctively blurry, there

\footnotetext{
15 On the depiction of motion-blur, see the discussions in Benovsky (2012) and Kulvicki (2016). (For a related discussion, also see Le Poidevin's (2017) treatment of 'Futurist' pictures.) While I say that to depict motion-blur is not to depict motion - a dynamic pattern of appearance over time - note that this is a result of the conception of depiction being operated with throughout, a conception not shared with Benovsky or Kulvicki.
} 
are also cases of things appearing to move without appearing blurry in this way, and there are cases of things appearing blurrily without appearing to move.

Do cases in which blur (caused as a result of motion) is depictively represented resemble the appearance of motion? I refer back to the above test on the relevant notion of resemblance. Paradigmatically static images presenting blur do not present/resemble the dynamic pattern of appearance of motion. A perceiver with ordinary vision is not acquainted with the visual property of motion in encountering the photograph of passing traffic, for example. The visual appearance of motion, that which is exemplified by the rotation of the second-hand of the clock, could not be learned from encountering such a photograph.

Consider a further auditory analogy. There is a phenomenological difference between seeming to experience several notes played on the piano spread across time and at a time; this is the difference between experiencing a bar and a chord of music. In the visual case, we might say that a long exposure photograph of passing traffic depicts motion-blur, or at least blur quite generally, but not motion per se. To present (motion-)blur is not to present something that resembles a dynamic pattern of appearance over time.

\section{3. Painting and the depiction of stasis}

Taking for granted that a typical painting does not present the appearance of dynamic activity unfolding over time, one might wonder whether a painting can nonetheless present the appearance of the inactive over time. The thought may be that the painting is capable of depicting stasis over an interval because the painting does appear to be capable of presenting the appearance of immobility over an interval. If this is the case, then a painting would be able to depict someone stood still, or more generally stasis, even though a painting cannot depict motion unfolding.

There is one reason to think that stasis cannot be depicted. Let us again distinguish between the appearance of F-ing and the appearance of an $\mathrm{O}$ that is F-ing. On this first proposal, we are to distinguish between depicting some object's activity as unfolding some specific way over some time, i.e. remaining still, and depicting some object as being engaged in some activity without depicting the very unfolding of that activity, i.e. as a stationary object. As with the case of motion, it is to be claimed that the former is not depicted in a painting while the latter may be. 
There may also be reason to think that stasis can be depicted in a painting. In defence of this claim, a theorist might again appeal to a comparison with motion pictures. It is plausible, it will be argued, that both a painting and a video recording can present the appearance of inactivity over time. There is not the same contrast to be drawn between the painting and motion pictures, from reflection upon one's experience, in the case of stasis as there is in the case of motion. If we take this second proposal, we might say that paintings are not capable of depicting dynamic time occupying properties, though they are capable of depicting non-dynamic time occupying properties, such as stasis. In what follows I demonstrate that this second proposal is unconvincing. In particular, I suggest that this proposal appears to be ruled out when we turn to the issue of the temporal extent that a painting does or does not depict. ${ }^{16}$

\section{Depiction and Duration}

Harris says that, of necessity, a painting depicts an instant (see Harris, 1744, pp. 56-63). The distinction between how motion pictures do, and paintings do not, depict dynamic patterns of appearance, might appear to lend prima facie plausibility to Harris's claim. Yet Gombrich argues that taking paintings to depict instants is problematic.

Gombrich says that we do not experience the world an instant at a time, like a series of static stills (see Gombrich, 1964, p. 297). Le Poidevin builds upon Gombrich's discussion, arguing that it would be problematic to say that paintings depict extensionless instants, as, on his view, this would be to suggest 'that we have a recognitional capacity for instants, and this seems highly dubious' (1997, p. 185). To put this claim in terms of appearances, to say that a painting depicts what we seem to experience as at an isolated instant would plausibly entail that things appear to us as being some given way at isolated instants, and this is to attribute us typical observers with implausible powers of discrimination.

When a subject reflects on the phenomenal character of her visual experience of an apparently instantaneous event, such as an object's starting to move, she cannot, in introspection, focus on the instant in isolation. There is a sense in which the subject can be said to be perceptually aware of

\footnotetext{
${ }^{16}$ A third possibility, though I won't explore it any further in this paper, is that there is no appearance of stasis; rather there is simply the presence or absence of the appearance of motion. While I will not explore whether this suggestion has any merit in the present context, it goes without saying that if there is no visual appearance of stasis, then stasis cannot be depicted in an image.
} 
the instantaneous event, but this is in virtue of being perceptually aware of something of a greater temporal extent (including the time before and after the object started to move). If we accept the plausible claim that things do not appear some given way at an extensionless instant in isolation, we seem to be committed to the claim that extensionless instants in isolation cannot be depicted. ${ }^{17}$

If we were to assume that paintings do not depict temporally extended intervals, unlike motion pictures, we now also have reason to hold that paintings do not depict instants, on pain of otherwise saying that things appear some given way to us at instants. These two claims would appear to conflict, if we make the further assumption that paintings must depict some duration (be it of zero extent, or some positive extent). To avoid the conflict we are to reject this further assumption.

We can maintain the distinction between what motion pictures and paintings depict, not by claiming that a painting depicts an instant whereas motion pictures depict extended intervals, but by claiming that a painting does not depict the duration of the scene depicted whatsoever. Yet, in doing so, this commits us to a negative answer to the question of whether a painting can depict stasis. To depict the standing still of a man, that man needs to be depicted as remaining stationary over some period of time; this is akin to how, to depict the movement of the man, that man needs to be depicted as changing his location over time. If paintings do not positively depict a temporally extended interval, then it would appear to follow that they cannot depict some object as remaining stationary over an interval (though, as suggested previously, a painting may present the appearance of an object as an object that is stationary, just as a painting may present the appearance of an object as an object that is moving). Hence, paintings are unsuitable to depict motion or stasis.

An alternative proposal a theorist may wish to support would be one on which the above assumption - that paintings do not depict temporally extended intervals - is rejected. (I don't wish to support such a proposal, but to clarify the detail of the proposal I believe that we should accept by way of a contrast with this alternative.) On this proposal it is said that a positive temporal extent can be depicted and so stasis may be depicted. It might be argued that when theorists deny that paintings depict a positive temporal extent, they tend to be motivated by the absence of the appearance of motion/activity in what is depicted, rather than the absence of some duration per se. Allowing that paintings do not depict such activity, one may nonetheless maintain the distinct

${ }^{17}$ For problems with the claim that we are experientially aware of instants in isolation, see the discussion in Phillips (2011), Shardlow (2019), and Soteriou (2013, ch. 4). 
claim that paintings depict a positive temporal extent, and this may allow a theorist to coherently claim that stasis can be depicted in a painting. ${ }^{18}$

Yet this alternative proposal faces difficult questions regarding the extent of the duration that is so depicted. Why, if a positive temporal extent is depicted, can motion not be depicted? Do all paintings depict the same positive temporal extent? Or rather, does the duration depicted vary from case to case? How are we to offer an answer regarding the duration that is so depicted? Such questions do not appear to have obvious or straightforward answers. While this proposal might outline a position in logical space, it isn't a proposal that we are independently motivated to endorse.

It is to be granted that the proposal that I am recommending may also seem to face difficult questions. For example, sometimes theorists - echoing Harris - describe a painting as capturing how a scene is at a moment in time. Motivated by such a description, theorists may further ask whether the objects/occurrences depicted in an image are depicted as happening at the same time? If so, which (period of) time is this? I wish to accept the first point, but to reject that the latter demands an answer.

I am convinced that two objects depicted in a single image are, at least typically, depicted as being contemporaneous. Consider again Degas's The Rehearsal. The dancers in the background are plausibly depicted as being contemporaneous with the seated dancer in the foreground. To press the point further, it would be hard to make sense of the claim that the seated dancer is not positively depicted as being contemporaneous with the seat upon which she is sitting, or the dress that she is wearing. However, we can allow that the objects and occurrences depicted are depicted as being some way concurrently - i.e. at the same time - while maintaining that there is no positive commitment to them being this way at an instant, or over a certain interval. There need not be a determinate answer to the second question in order for us to answer the first in the affirmative.

\footnotetext{
${ }^{18}$ Le Poidevin (1997) appears to offer just such an alternative, suggesting that a painting may depict the smallest perceivable temporal part of an interval, which he calls the 'specious instant' (also see the revised version of this discussion in chapter 7 of Le Poidevin 2007). As a reviewer for the journal suggests, one may then suppose that such an interval is of a positive extent, and that a positive extent is depicted, though this specious instant is not long enough to include the perception of a change in location. There is no doubt more to be said here, but what one says will depend upon contested issues in discussions of temporal experience. Here I simply wish to note that if one accepts the plausible sounding claim that no temporal part of the experience of an object moving lacks the phenomenology of motion, then an appeal to a specious instant as the shortest interval of time of which one could be aware, but which is not long enough for the perception of change, is no longer a coherent alternative. On the issue of the temporal minima that a subject is aware of in isolation, see the discussions cited in the previous footnote.
} 
I suggest that paradigmatically static images are, in this sense, temporally neutral on what is depicted. And yet, this is consistent with holding that - all else being equal - it is natural to take that which is depicted as being the way that it is at a given moment of time. We may suppose so without supposing that this is something that is depicted.

\section{Concluding Remarks}

Gombrich expressed regret that the representation of space in art has occupied the attention of art historians while the representation of movement has been neglected. On the conception of depiction assumed throughout, we can see one reason why comparatively little attention may have been paid to time and movement in painting: motion and duration (and stasis) are not depicted as such in paintings.

I have said that paintings do not depict the dynamic pattern of appearance of an activity as it unfolds over time, such as dancing; yet, paintings may depict an object as an object that is engaged in such an activity (though they don't depict the unfolding of that activity), such as the depiction of the dancer as dancing. I have also said that paintings do not depict an instant or an interval of time, but may rather depict a scene while remaining neutral on the duration of the scene; as a result, paintings do not depict stasis either. We may be able to depict movement, stasis and intervals of time in film, but on a canvas there is no time to move. ${ }^{19}$

\footnotetext{
${ }^{19}$ For helpful and stimulating comments and questions regarding topics relating to this paper, I am grateful to audiences at conferences and workshops held in Durham, Rijeka, and Cambridge. Thanks in particular to Tom Crowther, Matt Soteriou, Christoph Hoerl, Hemdat Lerman, Nick Young, Karen Simecek, Simon Wimmer, and Giulia Martina for illuminating discussions of the issues with which this article is concerned. I also thank the journal's anonymous referees for their probing questions and helpful suggestions. Some of the work towards this article was supported by a Research Fellowship at the University of Warwick on the AHRC project 'Time: Between Metaphysics and Psychology' (AH/P00217X/1), Principal Investigator Christoph Hoerl and Co-Investigator Teresa McCormack.
} 


\section{References}

Catharine Abell, 'Canny Resemblance', Philosophical Review, 118 (2009), 183-223.

Jiri Benovsky, 'Photographic Representation and Depiction of Temporal Extension', Inquiry, 55 (2012), 194-213.

Charlie Dunbar Broad, Scientific Thought (London: Kegan Paul, 1923).

Malcom Budd, 'On Looking at a Picture', in his Aesthetic Essays (Oxford: Clarendon Press, 2008a), $185-215$.

Malcolm Budd, 'The Look of a Picture', in his Aesthetic Essays (Oxford: Clarendon Press, 2008b), 216-238.

Gregory Currie, Image and Mind: Film, Philosophy and Cognitive Science (Cambridge: Cambridge University Press, 1995).

Carla Gottlieb, 'Movement in Painting', The Journal of Aesthetics and Art Criticism, 17 (1958), 22-33.

Ernst Gombrich, 'Moment and Movement in Art', Journal of the Warburg and Courtauld Institutes, 27 (1964), 293-306.

James Harris, Three treatises: The first concerning art. The second concerning music, painting, and poetry. The third concerning happiness (London: J. Nourse and P. Vaillant, 1744).

Robert Hopkins, 'Explaining depiction', Philosophical Review, 104 (1995), 425-455.

Robert Hopkins, Picture, Image and Experience: A Philosophical Inquiry (Cambridge: Cambridge University Press, 1998).

John Hyman, The Objective Eye: Color, Form, and Reality in the Theory of Art (Chicago: University of Chicago Press, 2006).

John Hyman, Depiction', Royal Institute of Philosophy Supplement, 71 (2012), 129-150.

John Hyman and Katerina Bantinaki, 'Depiction', The Stanford Encyclopedia of Philosophy, ed. Edward N. Zalta, (Summer 2017 Edition) URL = https://plato.stanford.edu/archives/sum2017/entries/depiction/ accessed 11 December 2017. John Kulvicki, 'Timeless Traces of Temporal Patterns', The Journal of Aesthetics and Art Criticism, 74 (2016), 335-346.

Gotthold Ephraim Lessing, Laocoon: An Essay upon the Limits of Painting and Poetry (1766, trans. Ellen Frothingham, 1873; rpt. New York: Noonday Press, 1969).

Robin Le Poidevin, 'Time, and the static image', Philosophy, 72 (1997), 175-188.

Robin Le Poidevin, The Images of Time: An Essay on Temporal Representation (Oxford: Oxford University Press, 2007).

Robin Le Poidevin, 'Motion and the Futurists: capturing the dynamic sensation', in Ian Phillips ed. The Routledge Handbook of Philosophy of Temporal Experience (Routledge, 2017). 
John Locke, An Essay Concerning Human Understanding, ed. Peter H. Nidditch, (Oxford: Clarendon Press, [1690] 1975).

Michael G. F. Martin, 'What's in a Look?', in Bence Nanay ed. Perceiving the World (Oxford: Oxford University Press, 2010), 160-225.

Michael G. F. Martin, 'Sounds and Images', British Journal of Aesthetics, 52 (2012), 331-351.

Brian O'Shaughnessy, Consciousness and the World (Oxford: Clarendon Press, 2000).

Christopher Peacocke, 'Depiction', Philosophical Review, 96 (1987), 383-410.

Ian Phillips, 'Indiscriminability and Experience of Change', The Philosophical Quarterly, 61 (2011), $808-827$.

Jack Shardlow, 'Minima sensibilia: Against the dynamic snapshot model of temporal experience', European Journal of Philosophy, 27 (2019), 741-757.

Matthew Soteriou, The Mind's Construction (Oxford: Oxford University Press, 2013).

Ambroise Vollard, Degas: an intimate portrait (New York: Crown, 1937).

Richard Wollheim, Painting as an Art: The Andrew W. Mellon Lectures in the Fine Arts (Princeton: Princeton University Press, 1987).

Richard Wollheim, 'On Pictorial Representation', Journal of Aesthetics and Art Criticism, 56 (1998), $217-226$.

Richard Wollheim, 'What Makes Representational Painting Truly Visual?', Aristotelian Society Supplementary Volume, 77 (2003), 131-147.

Nick Young and Clotilde Calabi, 'Can Movement Be Depicted?', Phenomenology and Mind, 14 (2018), $170-9$. 